\title{
PROCEDIMENTO PARA A CONSTRUÇÃO DE UMA AUDIODESCRIÇÃO CONGELANDO A TELA: UM ESTUDO DE CASO PARA ENSINAR CONCEITOS DE FÍSICA ${ }^{1}$
}

\author{
Sabrina Gomes COZENDEY ${ }^{2}$ \\ Maria da Piedade Resende da COSTA ${ }^{3}$
}

RESUMO: O presente trabalho tem como objetivo descrever o desenvolvimento de um procedimento para uma audiodescrição de um recurso educativo para o ensino de Física distribuído pelo Ministério de Educação (MEC). Para isso utilizou uma estratégia não muito comum ao fazer a audiodescrição: o congelamento da tela. $\mathrm{O}$ vídeo audiodescrito foi testado em dois momentos, primeiro com um grupo de 14 pessoas que eram cegas ou tinham baixa visão. Em um segundo momento o vídeo audiodescrito foi testado junto a uma turma da Educação de Jovens e Adultos (EJA) que tinha um aluno com baixa visão incluído. Os resultados apontam que a audiodescrição feita em momentos em que a tela é congelada pode ser uma solução para audiodescrever vídeos prontos, que não tenham intervalos suficientes entre as falas para que a audiodescrição seja feita. Os alunos cegos consideraram a estratégia diferente, alguns gostaram mais que outros, contudo a estratégia foi aprovada, pois a audiodescrição cumpria com sua função: tornava verbal o que era apresentado visualmente. Para os alunos da EJA o congelamento da tela não é visto como incomodo, e não atrapalhou o processo de ensino e de aprendizado.

PALAVRAS-CHAVE: Audiodescrição. Ensino de física. Turmas inclusivas.

\section{Introdução}

Nas últimas décadas a inclusão de pessoas com necessidades educacionais especiais nas escolas regulares se tornou uma realidade. Aos poucos as escolas estão recebendo alunos que necessitam de práticas educacionais diferenciadas.

Dentre estes alunos que apresentam necessidades educacionais especiais estão os alunos com baixa visão e os alunos cegos. Estes alunos necessitam de práticas educacionais que valorizem os sentidos não visuais.

\footnotetext{
${ }^{1}$ Trabalho financiado pela FAPESP - Processo 2013/05004-4.

2 Doutora em Educação Especial. UFSCar - Universidade Federal de São Carlos. Pesquisadora Associada. São Carlos - SP - Brasil. 13565-905 - sgcfisica@yahoo.com.br.

3 Doutora em Psicologia (Psicologia Experimental). USP - Universidade de São Paulo. Docente permanente do Programa de Pós-Graduação em Educação Especial. UFSCar - Universidade Federal de São Carlos. São Carlos - SP - Brasil. 13565-905 - piedade@ufscar.br.
} 
Assim, na sua escolarização, o aluno com deficiência visual (DV) necessitará de estímulos, oportunidades e recursos adequados, não visuais, que auxiliem sua aprendizagem e contribuam para o desenvolvimento das suas habilidades.

Torna-se então, importante desenvolver estratégias de ensino adequadas às necessidades do aluno com deficiência visual, pois segundo Orrico, Canejo e Fogli (2009), a falta de recursos adequados a um aluno com deficiência visual pode prejudicar o seu desenvolvimento e a sua aprendizagem.

Um exemplo de recurso inadequado ao aluno cego são os desenhos e representações apresentadas nos livros que só podem ser percebidos por meio da visão. Outro exemplo pode ser observado no momento que o professor utiliza uma animação, simulação ou um vídeo que tem um caráter audiovisual e que, em alguns casos, não possibilita a compreensão da mensagem apenas com o recurso do áudio, e assim, o aluno com DV não consegue compreender adequadamente a mensagem do recurso didático.

Contudo, existe uma estratégia que pode tornar recursos didáticos como animações, simulações, vídeos entre outros, compreensíveis ao aluno com DV, a audiodescrição (AD).

\section{A audiodescrição}

Silva et al. (2010) diz que a AD é um serviço ou recurso cujo alvo são pessoas com DV e se caracteriza pela narração adicional de aspectos visuais da imagem tais como: vestuário, linguagem corporal, aspectos da cena (quarto, parque, árvores, carros, semáforos), entre outros. A AD deve descrever de forma concisa e objetiva as imagens apresentadas.

$\mathrm{A} \mathrm{AD}$ pode aumentar o acesso às artes para todas as pessoas que frequentam exposições em museus, teatro, pessoas que assistem televisão ou cinema, e pode até mesmo melhorar a alfabetização das crianças (SNYDER, 2005). A audiodescrição "[...] é útil para quem quer realmente observar e apreciar uma perspectiva mais completa em qualquer evento visual, mas é especialmente útil como uma ferramenta de acesso para pessoas cegas ou com baixa visão.” (SNYDER, 2005, p.3).

Para realizar a $\mathrm{AD}$ é preciso construir um repertório do que é necessário ser informado para que o ouvinte possa compreender a construção imagética (SILVA et al., 2010). Segundo Silva et al. (2010, p.10), a AD “[...] deve ser clara, objetiva e concisa, 
com linguagem direta e apropriada de acordo com o público-alvo (criança, jovem, adulto)".

Ao produzir uma $\mathrm{AD}$ para o cinema ou para uma peça, as audiodescrições são preparadas para serem introduzidas nos intervalos entre as falas. Quando uma peça ou filme é desenvolvido nem sempre há a preocupação de se deixar intervalos entre as falas para que a $\mathrm{AD}$ possa ser feita, o que em muitos casos inviabiliza a $\mathrm{AD}$ da obra. Para Udo e Fels (2010) o correto seria que a audiodescrição fosse pensada enquanto o filme é desenvolvido. Para os autores os projetos de multimídia devem ter um design universal desde a concepção da proposta.

A questão levantada é muito importante, seria muito mais fácil fazer a $\mathrm{AD}$ se esta fizesse parte da concepção da proposta, pois uma das maiores dificuldades da audiodescrição é conseguir informar os aspectos visuais de suma importância para a compreensão do filme nos intervalos entre os diálogos, às vezes os intervalos são pequenos, ou às vezes há uma música de fundo que também é importante para a história.

Se o não planejamento da $\mathrm{AD}$ como parte da obra pode dificultar ou impedir que a $\mathrm{AD}$ seja realizada, como a $\mathrm{AD}$ poderia ser utilizada no ensino? A maior parte dos recursos educacionais não é desenhada pensando na possibilidade de um dia ser audiodescrita. Muitos vídeos educativos não têm intervalos entre as falas suficientes para que a $\mathrm{AD}$ possa ser realizada.

Um estudo desenvolvido por Camara e Espasa (2011) pode apresentar uma possível estratégia para audiodescrever vídeos educacionais que não tenham espaços suficientes entre as falas para que a $\mathrm{AD}$ seja realizada. No trabalho intitulado: "The Audio Description of Scientific Multimedia" Camara e Espasa (2011) apresentam uma discussão sobre um estudo de caso: a audiodescrição do documentário "The Rhythms of Life". O documentário foi audiodescrito em espanhol para os membros da Organização Nacional de Cegos Espanhóis (ONCE). O documentário de 1995 foi audiodescrito em 1997, uma das caraterísticas mais marcantes da AD realizada para este documentário foi que ela aumentou a duração do filme em 15 minutos, de 60 minutos para 75.

Isto ocorreu porque no início do documentário a tela é congelada para que informações relevantes fossem audiodescritas. Segundo os autores do trabalho o congelamento da tela para fazer a $\mathrm{AD}$ não ocasionou problemas de sincronia, pois foi apresentado somente a pessoas cegas. Assim, esta técnica só pôde ser utilizada porque o documentário não foi utilizado no cinema, se assim fosse, seria impossível congelar as 
imagens para fazer a audiodescrição, pois acarretaria um problema de sincronização que poderia ser incomodo a pessoas videntes.

Os pesquisadores espanhóis apontam uma possibilidade para fazer a AD quando não existem intervalos entre as falas dos atores. Contudo, segundo os autores, o congelamento da tela para fazer a AD só seria viável se o vídeo fosse utilizado somente com pessoas cegas.

Neste trabalho utilizamos a proposta de fazer a $\mathrm{AD}$ em momentos em que a tela é congelada para audiodescrever um vídeo de ensino de Física. A grande diferença do trabalho espanhol para o que realizamos, é que o nosso recurso educativo foi desenvolvido para ser utilizado em sala de aula, com alunos com e sem deficiência visual. No caso espanhol eles apenas utilizaram o documentário com pessoas cegas. E a $\mathrm{AD}$ feita na tela congelada pelo grupo espanhol aconteceu no início do vídeo, para antecipar as informações importantes sobre o documentário. No caso deste trabalho as audiodescrições foram feitas ao longo do vídeo, e assim a tela foi congelada algumas vezes.

O objetivo deste trabalho é realizar a descrição de um procedimento de uma audiodescrição, congelando a imagem em momentos em que os intervalos entre as falas forem insuficientes para fazer a AD. Também se busca neste trabalho utilizar o vídeo audiodescrito como um recurso de ensino de física junto a alunos com e sem deficiência visual. Para assim descobrir se a formatação da $\mathrm{AD}$, feita congelando a tela, poderá ser utilizada em vídeos educacionais para serem usados em salas regulares inclusivas de ensino.

\section{Construindo a audiodescrição}

Foi desenvolvida uma $\mathrm{AD}$ de um vídeo de ensino de Física distribuído pelo MEC.

Foi escolhido o vídeo "Os Curiosos - Trabalho e Potência", desenvolvido pelo Instituto Brasileiro de Educação e Tecnologia de Formação a Distância (IBTF) (BRASIL, 2010) para ser audiodescrito no trabalho aqui apresentado.

No quadro1 é apresentada a sinopse do vídeo. 
Quadro1 - Sinopse do vídeo

\section{Sinopse do vídeo "Os Curiosos - Trabalho e potência":}

\section{Essa atividade irá abordar o tema "trabalho e potência".}

Primeiramente o professor explica o conceito de trabalho. Para auxiliar a compreensão do conceito de trabalho é apresentada na tela uma imagem em que há uma pessoa sentada em uma cadeira, uma caixa no chão e uma mesa, na parede a um objeto que parece um relógio (mas não é). Esse objeto é redondo como um relógio, possui um único ponteiro que fica apontado para baixo, quando a pessoa da imagem levanta, senta, ou pega a caixa no chão, o ponteiro desse objeto oscila para que a pessoa vidente possa perceber que nesta ocasião houve trabalho. Os conceitos de trabalho e o de potência são discutidos e apresentados na forma desafios propostos a duas equipes de estudantes, a preta e a vermelha. A equipe vermelha realizará uma demonstração onde irão produzir corrente elétrica com auxílio de uma bicicleta e de um dínamo. Ao pedalar a bicicleta, o deslocamento da roda irá acionar o dínamo que irá produzir uma corrente elétrica responsável por acender uma lâmpada (BRASIL, 2010). A equipe preta realizará uma demonstração onde dois estudantes levantarão alguns pesos com auxílio de cordas realizando um trabalho. No decorrer da apresentação os estudantes irão cronometrar o tempo gasto no movimento e descobrir quem aplicou maior potência durante o experimento.

Fonte: Brasil (2010).

Como pode ser percebido na sinopse do vídeo, este poderia ser dividido em três partes, que poderiam proporcionar diferentes análises. A primeira parte é totalmente visual: a imagem apresentada no momento em que o professor explica o conceito só pode ser observada por quem enxerga. Na segunda parte do vídeo será analisado o funcionamento de um dínamo na produção de eletricidade para acender o farol da bicicleta. Essa explicação pode ser compreendida por uma pessoa que tenha memória visual ou baixa visão. Na terceira parte do vídeo é discutido o conceito de potência em uma situação em que duas pessoas puxam um peso preso a uma corda para o segundo andar de um prédio, esta situação teoricamente poderia ser compreendida por todos os alunos.

No desenvolvimento da $\mathrm{AD}$ em alguns momentos a tela foi congelada para que pudesse ser feita. Esta estratégia foi utilizada nos instantes em que o espaço entre as falas dos atores era muito pequeno, impossibilitando a AD. Nas situações em que entre os intervalos entre as falas havia uma faixa musical pode-se fazer as audiodescrições utilizando a estratégia de diminuir o volume do filme para que a AD pudesse ser ouvida. Para fazer a $\mathrm{AD}$, a tela foi congelada cinco vezes ao longo do vídeo.

A AD do filme "Os Curiosos - trabalho e potência" foi centrada na ação, ou seja, foram audiodescritas as ações dos personagens e não aspectos físicos e 
vestimentas. Como o objetivo do vídeo é explicar um conceito, a ação realizada no filme é a parte mais importante, a parte que precisa ser audiodescrita para que o aluno possa compreender o conceito. As vestimentas e os aspectos físicos dos personagens não influenciam na compreensão do conceito e assim não há uma necessidade de audiodescrever estes aspectos. É preciso considerar que a AD deve descrever somente o que é indispensável para a compreensão do vídeo, que neste caso tem como objetivo explicar um conceito. Se todos os elementos do vídeo forem audiodescritos, ele se tornará desagradável a uma pessoa vidente.

Como o vídeo audiodescrito seria utilizado em uma turma regular inclusiva, nos momentos em que houve a audiodescrição na tela congelada, foi apresentado na tela um texto com as informações que estavam sendo narradas, assim não foi cortada a sequência do filme. Com essa estratégia garantiu-se a sincronização do vídeo.

$\mathrm{Na}$ segunda parte do vídeo, optou-se por deixar a explicação da 'equipe vermelha' até o final, somente depois fazer a audiodescrição e para garantir que o aluno cego iria compreender a explicação, a cena foi repetida. Assim, na segunda parte do vídeo houve a explicação da 'equipe vermelha', a audiodescrição do que ocorreu, e a repetição da explicação.

Com a $\mathrm{AD}$ e a repetição de uma explicação da equipe vermelha, o filme " $O s$ Curiosos - Trabalho e potência" ganhou alguns minutos a mais: o filme original tinha 7:57 minutos, o filme audiodescrito ficou com 10:24 minutos, 2:27 minutos a mais.

Para desenvolver a AD foi utilizado o software Audacity 1.3.12-beta (AUDACITY OPEN SOURCE DEVELOPMENT TEAM, 2011) para gravar a segunda faixa de áudio a ser acrescentada no filme. A edição do filme, momento em que as faixas de áudio correspondente as audiodescrições foram acrescentadas ao filme, foi desenvolvida no software Corel Vídeo Studio 12 (COREL, 2011).

\section{Testando a audiodescrição e suas potencialidades}

O vídeo audiodescrito foi testado em duas situações buscando identificar se o formato da audiodescrição estava adequado. Primeiramente o vídeo foi apresentado a pessoas cegas e com baixa visão, 14 alunos participaram desta etapa. Em uma segunda situação de análise, o vídeo audiodescrito foi utilizado em uma turma da EJA que tinha um aluno com baixa visão incluído e 12 alunos participaram desta etapa. 
Nestas duas situações de uso do vídeo audiodescrito foi possível analisar se o formato da audiodescrição foi bem recebido pelos alunos, e, se a mensagem apresentada no vídeo foi compreendida.

Buscando valorizar as discussões, os alunos cegos ou com baixa visão foram divididos em três Grupos. O grupo 1 formado por quatro participantes (A, C, J, e T) assistiu ao vídeo e participou das discussões em grupo. Os participantes assistiram ao vídeo sem audiodescrição em um dia, e em outro dia assistiram ao vídeo com a audiodescrição, as discussões propostas ocorreram logo após a apresentação do vídeo. O grupo 2 era formado por cinco participantes $(\mathrm{B}, \mathrm{D}, \mathrm{E}, \mathrm{L}$ e $\mathrm{O})$ que assistiram ao vídeo e participaram das discussões individualmente. Os participantes do grupo 2 assistiram ao vídeo com audiodescrição em um primeiro momento, e em um segundo momento assistiram ao vídeo sem a audiodescrição, as discussões propostas ocorreram logo após a apresentação do vídeo. O grupo 3 era formado por cinco participantes (F, M, N, R e S) que assistiram ao vídeo e participaram das discussões individualmente. Os participantes do grupo 3 assistiram ao vídeo sem audiodescrição em um primeiro momento, e em um segundo momento assistiram ao vídeo com a audiodescrição, as discussões propostas ocorreram logo após a apresentação do vídeo.

Para analisar a compreensão do vídeo, da audiodescrição e do conceito apresentado, foram desenvolvidos alguns questionamentos para guiar as discussões que ocorreram após a apresentação dos vídeos. Dentre estes questionamentos estão: o que você compreendeu do vídeo? Como você explicaria esse vídeo para um amigo? O que você entendeu da audiodescrição? Na situação da que a equipe vermelha em que a aluna diz: "a força pode ser aplicada aqui”, a audiodescrição só é feita depois e para dar sentido a explicação a cena é retomada. Em relação a esta situação, a estratégia foi adequada? Você acredita que a explicação ficaria melhor entendida se a audiodescrição fosse feita imediatamente após a fala? A repetição da cena ajuda a compreender o filme? A audiodescrição feita em momentos em que a tela é congelada incomoda?

$\mathrm{Na}$ segunda situação de uso do vídeo audiodescrito, primeiramente foi apresentado o vídeo sem $\mathrm{AD}$ e foi desenvolvida uma pequena discussão com os estudantes quando lhes foi solicitado que respondessem a uma simples questão: como vocês explicariam o vídeo a um amigo? Após as discussões foi apresentado o vídeo com a AD. Após a apresentação do vídeo foi solicitado aos alunos que respondessem novamente a questão: como vocês explicariam o vídeo a um amigo? A intenção dessa estratégia era deixar os alunos a vontade para falar sobre o que realmente lhes chamou a 
atenção no vídeo. Ao final da aula os alunos foram questionados sobre o formato do vídeo, que em alguns momentos tinha a tela congelada para que a audiodescrição fosse realizada. Os alunos também foram questionados sobre qual dos dois vídeos, com e sem audiodescrição, eles gostaram mais, e por quê. E ao final foi eleito qual vídeo apresentava melhor os conceitos, e assim poderia favorecer a aprendizagem. Os alunos da turma da EJA foram divididos em 4 grupos, cada grupo tinha 3 alunos. Nas discussões os alunos foram identificados por letras, ou pelo grupo que pertencia.

As discussões realizadas nas duas situações de uso do vídeo audiodescrito foram gravadas para favorecer a análise posterior. A professora mediadora foi identificada pela letra P, a professora da turma da EJA foi identificada como: professora da turma.

Este trabalho consiste em uma pesquisa descritiva qualitativa que buscou nas análises das discussões realizadas com os participantes, informações que validassem a estrutura da audiodescrição desenvolvida, utilizando a estratégia de congelar a imagem para que a AD pudesse ser feita.

\section{Análise e discussão dos dados coletados}

Para favorecer a apresentação e análise dos dados coletados nas duas situações de uso do vídeo, estes serão apresentados separadamente. Os dados foram divididos em três categorias: formato da $\mathrm{AD}$, repetição da explicação e comparatória (vídeo audiodescrito x vídeo sem audiodescrição).

\section{Dados coletados com os alunos cegos e com baixa visão}

\section{$\underline{\text { Formato da AD }}$}

$\mathrm{Na}$ categoria formato da AD buscou-se analisar a forma como a AD foi feita, em momentos em que a tela foi congelada. Para facilitar a análise são apresentados alguns trechos das discussões desenvolvidas com os alunos em relação ao formato da AD:

Grupo 1:

J: Eu gostei. Tem que ser assim, sem a audiodescrição não é bom.

T: Gostei da forma como foi feita.

M: Assim é melhor.

\section{Grupo 2:}


B: Melhor. Uma maravilha para quem não enxerga.

P: Eu congelei a imagem para fazer a audiodescrição porque não tinha espaço.

D: Que nem o telecurso 2000, não tem espaço. Para mim não atrapalha. Mas quando atrapalhar você para e explica para as pessoas.

L: Eu concordo com você que o filme é corrido e que tem que fazer pausas, mas talvez as falas possam ser menores, resumidonas assim. Uns dizeres mais objetivos e mais rápidos, justamente para não aumentar muito o tempo do vídeo. Se um vídeo audiodescrito for muito diferente de um vídeo normal, o fator tempo vai fazer diferença. Bem é uma opinião minha tá. No todo está muito legal, muito bem feita a audiodescrição, não está faltando informações, informações importantes né. A audiodescrição o objetivo não é que tenha todas as informações, mas as informações que possibilitam entender o vídeo, $e$ isso tem.

\section{Grupo 3:}

F: A audiodescrição dessa forma é interessante, ele instrui, na hora que ele tem que descrever ele para, tem pausa, aí você sabe realmente o que ele quer descrever. Porque eu já participei de filme com audiodescrição e não tem pausa. Este filme que eu estou falando para você não tem pausa, então às vezes dá para entender, mas você tem que estar o tempo todo ligado. Bem, em tudo a gente tem que estar, principalmente quem não enxerga.

$P: O$ senhor achou que essa pausa foi importante?

$F$ : É importante. Esta pausa, ela é interessante, porque ela marca realmente o ponto que ele está te explicando, que aí depois que ele para e explica ele continua. É importante, é interessante.

R: Eu achei assim, que ficou muito legal. Ficou diferente né. Eu acho que vale a pena sim ter a audiodescrição, como eu disse: eu sou muito a parte quanto mais próxima a matéria ela vier melhor. Eu acho que também não dá problema você fazer a audiodescrição assim da forma que vocêfez.

Os participantes aprovaram a estratégia de congelar a imagem para fazer a audiodescrição. O participante L, que conhece bem vídeos com audiodescrição, disse que talvez as falas pudessem ser menores para não aumentar muito o tempo do vídeo, no entanto, disse que a audiodescrição estava muito boa. $\mathrm{O}$ participante $\mathrm{F}$ disse que a audiodescrição feita congelando a imagem, ou com pausa na explicação, que era como ele percebia, era melhor, pois conseguia saber exatamente o que estava sendo audiodescrito. Já a participante $\mathrm{R}$ disse que as duas formas de audiodescrição são válidas, a utilizada nesta pesquisa não é comum, mas ficou boa e estava clara. É claro que o mais adequado seria fazer a audiodescrição nos intervalos entre as falas, contudo, 
se esse intervalo não existe, o congelamento da tela para fazer a audiodescrição pode ser uma opção, visto que nenhum participante relatou um incomodo com a estratégia utilizada para fazer a audiodescrição.

\section{$\underline{\text { Repetição da explicação }}$}

Nesta categoria buscou-se analisar se a estratégia utilizada para fazer a audiodescrição da fala da equipe vermelha (em que se optou por fazer a explicação, depois audiodescrever o que acontecia, e repetir a explicação) era pertinente ou deveria ser modificada. Em relação a este questionamento os participantes disseram:

\section{Grupo 1:}

J: Para mim ficou claro que não havia a necessidade da bicicleta está em movimento, andando, tá parada. Você pedala com ela parada desde que a catraca funcione.

P: Para você $T$, você acha que assim foi melhor repetindo, dizendo que esse "aqui" era o pedal. Ficou mais fácil?

$T: \dot{E}$.

P: Para você M que tem baixa visão, o que você acha? Está bom com essa audiodescrição ou ela é desnecessária?

M: Tá melhor.

P: Com a repetição pode-se entender o conceito melhor, porque repete a explicação?

T: Sim, entende melhor.

J: Eu entendi desde o começo, quando ele fala: "aqui", deve estar se referindo ao pedal. Mas pode deixar.

\section{Grupo 2:}

P: Então, agora deu para entender o porquê de repetir a explicação. O que você achou?

D: Acho melhor deixar a audiodescrição, e repetir a explicação.

L: No meu caso seria desnecessário repetir a parte que repetiu.

O:É melhor repetir. Tem muita gente que talvez não vai entender, né. Que tem muita gente que não anda de bicicleta e não sabe disso.

\section{Grupo 3:}

P: Quando ela falou: "essa força está sendo aplicada aqui", retomou a cena do que tinha acontecido. Você achou disso?

F: Ficou claro. Ainda mais que a gente já viveu tudo isso né. Mas mesmo assim fica bem claro, bem mais claro, bem mais fácil de compreender. É como se você tivesse visualizando né. Ela fala a força aqui, aí descreve que a força aqui está se referindo a força no pedal, 
aí você quase que visualiza. E como se eu estivesse vendo. Eu estava imaginando, enxergando na minha mente a catraca girando, quando ela falou a força aqui, aí eu pensei em todo aquele aparato da corrente e a pessoa pedalando, entendeu? Deixa bem claro.

Em relação a estratégia de apresentar a explicação, fazer a audiodescrição e repetir a explicação, alguns participantes acharam desnecessário, outros acharam necessário. Nenhum deles disse que a repetição atrapalha a compreensão do vídeo, ou que ficaria melhor sem a audiodescrição, disseram que não precisava, mas que estava bom. Com as discussões pode-se perceber que para pessoas mais atentas a repetição é desnecessária e para pessoas mais desatentas a repetição chama a atenção e explica melhor o que ocorre. Também se pode perceber que os alunos cegos congênitos preferem a audiodescrição mais objetiva e que os alunos que tem memória visual preferem audiodescrições mais detalhadas. Assim, pode-se perceber que a AD pode ser feita após a apresentação da cena, e se está for retomada novamente se garante que todos compreenderam a explicação.

\section{Comparatória (vídeo audiodescrito x vídeo sem audiodescrição)}

Para favorecer a análise e comparar o vídeo com $\mathrm{AD}$ e o vídeo sem $\mathrm{AD}$, serão apresentados alguns trechos das discussões desenvolvidas após a apresentação de cada vídeo. Assim, busca-se observar o que pôde ser compreendido de cada vídeo.

Primeiramente são apresentadas algumas discussões desenvolvidas com os alunos após assistirem ao vídeo sem audiodescrição:

\section{Grupo 1:}

P: Mas vocês conseguiram entender do que estava falando?

T: Não.

$[\ldots]$

P: Da onde eles estavam puxando o peso? Tinha um lugar? Era um lugar mais alto, mais baixo, era aonde?

$C:$ É eles estavam no chão e tem que puxar até no segundo andar parece.

J: Da mesma altura. Só que um estava com mais força. Mais potência.

\section{Grupo 2:}

B: Nossa sem o áudio não dá para entender nada do que está acontecendo ali. 
$P$ : A primeira parte é a mais difícil de compreender.

B: É, é impossível. Porque você não sabe o que está se passando ali sem áudio.

P: A segunda parte, você sabe o que é uma bicicleta então ...

$B$ : É, como ela vai explicando.

P: É mais fácil?

B: Fácil não, porque você não sabe se a bicicleta vai se locomover ou não, ou, o que acontece.

$[\ldots]$

E: É para a pessoa que enxerga né? Ele não especificou que objeto é esse, como foi especificado na primeira parte.

$[\ldots]$

O:Falta bastante informação. Se eu não tivesse visto primeiro (com a $A D)$ eu não falava nada, sei lá o que está acontecendo.

Grupo 3:

P: O senhor entendeu que conceito estava sendo trabalhado no vídeo?

F: Não, eu não peguei.

$[\ldots]$

P: $O$ que o senhor conseguiu entender desta parte?

N:Tem uma pessoa falando.

$[\ldots]$

P: Você conseguiu entender do que estava falando o vídeo?

R: Fazem um trabalho na física, né. Foi o que eu entendi.

$[\ldots]$

S: Entendi que tinha um peso, uma lâmpada, da corrida de bicicleta.

P: Tinha uma corrida de bicicleta?

S: É. Ele pedalava, pedalava, pedalava, aí a lâmpada acendia forte. Aí ele pedalava, pedalava, e a lâmpada queimou.

Nas discussões realizadas com o grupo 1 e 3 que assistiram primeiro ao vídeo sem audiodescrição é possível perceber que os participantes não compreenderam todas as informações essenciais para entender o vídeo. Alguns participantes apresentaram interpretações erradas do que ocorria, ou seja, além de dificultar a compreensão, o vídeo sem a audiodescrição pode levar a uma compreensão errada do que ocorre no vídeo. Um exemplo desta situação é apresentado na fala do participante $S$, que acreditou que estava ocorrendo uma corrida de bicicleta. 
Como os participantes do grupo 2 assistiram ao vídeo sem audiodescrição em um segundo momento, depois de terem assistido ao vídeo com a audiodescrição, relataram a diferença que perceberam no vídeo quando não havia a audiodescrição. Os participantes disseram que não dava para saber o que acontecia, um deles perguntou se o vídeo era para quem enxerga, como quem diz: esse filme não é adequado para uma pessoa cega.

Continuando a análise dos vídeos, são apresentados, a seguir, alguns trechos das discussões realizadas após os alunos assistirem ao vídeo com audiodescrição:

Grupo 1:

J: Levantou uma corda. Numa ponta estava o peso.

C: Eles estavam no sobrado. O peso estava no chão.

P: Eles estavam em que parte do sobrado?

T: Segundo andar.

C: Que mede 6 metros do chão.

P: Que que eles fizeram lá?

T: Puxaram a corda.

C: É puxaram a corda com o peso.

[...]

J: Outra coisa que eu entendi e que para acontecer isso aí a bicicleta não precisava está andando.

T: Não.

C: Ela tava parada.

J: Parada. O que estava fazendo força, parada você pode pedalar que gera o deslocamento e aí você tem a força, não sei se vocês perceberam isso.

Grupo 2:

B: Ah, eles estavam pedalando uma bicicleta não era?

P: Sim. O que acontecia quando ele pedalava a bicicleta?

B: Acendia a luz. Estava pedalando a bicicleta mais ela não estava saindo do lugar. Não tinha deslocamento.

$P$ : Não tinha deslocamento da bicicleta.

B: Deslocava a catraca.

$[\ldots]$

P: Se você fosse explicar o vídeo para um amigo, como você explicaria esse vídeo?

D: Que ele trata o conceito de trabalho que é deslocamento e força. Daria o exemplo da caixa, se ele pega a caixa e só segura a caixa, e 
ele não teve deslocamento então não há força, se ele levanta e segura a caixa já há trabalho, desculpa é trabalho não força.

\section{$[\ldots]$}

E: Está falando sobre energia cinética, sobre a potência. Que ele pedalando vai movimentar o dínamo, vai movimentar a catraca, que a energia cinética do Pedro vai fazer com que tem força no pedal, que movimenta o dínamo, a catraca e por sua vez produz energia na lâmpada.

[...]

O: Ele falou de pegar um peso. E esse dínamo da bicicleta tinha muito disso aí antigamente na roça. Eu lembro que eu tinha uma bicicleta que tinha isso. Se você conhece um dínamo gerador. Um papel de alumínio assim não iluminava mais, você podia pedalar o quanto que fosse que não iluminava mais.

\section{Grupo 3:}

F: Com a audiodescrição está bem melhor né. Está bem mais claro, explicado, a gente entende com mais precisão. Aquele negócio que você me explicou como é mesmo?

P: $O$ indicador de trabalho.

F: $O$ indicador. Em um primeiro momento eu perguntei, mas eu entendi, é como se fosse um painel, com forme o movimento ele vai para a direita ou vai para a esquerda, não é isso?

$P: \dot{E}$.

F: $O$ outro (vídeo sem AD) foi semelhante as aulas minhas. Eu forçando para intender e esse outro não. Esse outro (vídeo com AD) já dá para entender que tem uma equipe vermelha, que tem uma equipe preta. Já dá para saber os personagens. É interessante, é muito interessante. Se houvesse isso, na verdade eu acho que é isso mesmo, para mim está não vou dizer perfeito, o perfeito para mim pode ser uma coisa para você pode ser outra né, mas está ótimo.

P: Se você fosse contar esse filme para um amigo o que você diria para ele?

F: Eu iria falar que a experiência com a audiodescrição teve mais possibilidade de você conseguir ter resultados melhor, mais perfeitos. Sem a audiodescrição se pega, agora com a audiodescrição você pode dizer que dá para pegar tudo. Até o cálculo que ela fez ali, com a audiodescrição foi muito mais fácil para mim. $O$ trabalho, o rapaz. fez em 9 segundos, e ela fez em 8,2. Entendeu? Para mim até nesses detalhes foi mais perfeito para entender.

[...]

P: A diferença é que tem uns comentários, que vão falando as coisas.

M: É, esclarece melhor, né.

P: Falou que o cara estava subindo o peso, a senhora entendeu isso, que ele estava subindo o peso para varanda?

M: Isso. Que estava subindo para o segundo andar né. 
P: A senhora tinha entendido isso antes?

M: Não, a primeira vez não falou. Só falou que o cara levantava o peso.

[...]

M: É. A bicicleta também, eu pensei que eles estavam pedalando ela correndo, só que eles estavam pedalando ela parada.

P: Isso.

M: Ela estava parada com ele pedalando. Esse agora eu entendi que a bicicleta estava parada.

As falas dos participantes deixam claro que o vídeo com audiodescrição proporciona uma melhor compreensão do vídeo, e assim é melhor que o vídeo sem a audiodescrição. Os participantes declararam que algumas coisas só puderam compreender com o vídeo audiodescrito. Estas coisas, tais como: a bicicleta estava parada, era a catraca que girava, são de suma importância para a compreensão do vídeo.

É possível perceber ao observar as discussões feitas após o vídeo sem AD e com $\mathrm{AD}$ que após assistirem ao vídeo com $\mathrm{AD}$ os participantes foram capazes de explicar o que ocorria no vídeo apresentado em um número maior de detalhes.

Após assistir ao vídeo audiodescrito os participantes disseram que estavam interpretando o vídeo de forma diferente e com a AD compreenderam o que ocorria. As falas a seguir relatam esta afirmação:

C: Eu estava pensando que eles estavam no chão e estavam puxando com uma carretilha e não estavam. Eu pensei que eles estavam no chão e tinha uma carretilha. É o contrário, eles estão encima do prédio o peso está embaixo. A audiodescrição ajudou a esclarecer.

T: Sabia que eles estavam puxando a corda, mas eu não sabia, pensei que era embaixo.

[...]

$J$ : Eu só tinha percebido o barulhinho, mas o restante não. Aquela mesa e a caixa no chão eu não sabia. Ele falou da mesa, eu não tinha percebido esse detalhe ainda. Isso aí, eu nem imaginava agora eu sei.

$[\ldots]$

F: $O$ detalhe que ficou claro com a audiodescrição foi quando ela falou a força "aqui", quando ela falou a força "aqui" primeiro no vídeo sem a audiodescrição, eu entendi que ela estava falando a força na catraca. Mas com a audiodescrição ela explicou a força no pedal. Certo? A força "aqui", a catraca gira. Na primeira passagem, sem a audiodescrição, eu entendi que era na catraca. Ela falou "aqui" é só no pedal. Tem uns detalhes interessantes. Esclareceu, esclareceu, nesse sentido foi interessante. 
Quando perguntados sobre qual vídeo era melhor, todos os alunos cegos e com baixa visão disseram que vídeo com audiodescrição era melhor, e permitia compreender mais informações. Com a análise dos dados coletados, foi observado exatamente isto. Ao assistirem ao vídeo sem $\mathrm{AD}$ os participantes não compreenderam todos os elementos importantes para entender o vídeo, e em alguns momentos concluíram de forma errada o que acontecera no vídeo. Com o vídeo audiodescrito os participantes compreenderam um número maior de detalhes e entenderam mais adequadamente o que era apresentado no vídeo.

\section{Dados coletados com os alunos da EJA}

Os alunos da EJA foram muito pontuais em sua participação no estudo. Foram muito objetivos nas respostas, e assim falaram pouco. Nas discussões das categorias de análise a seguir, será possível observar esta informação.

\section{Formato da AD:}

Nas discussões realizadas com os alunos da EJA foi perguntado aos alunos se o congelamento da tela para fazer a $\mathrm{AD}$ gerava algum incomodo. A seguir são apresentadas as respostas dadas a esse questionamento:

P: Gente uma última pergunta: quando congela a imagem para fazer a audiodescrição, para a imagem e faz a audiodescrição, vocês acharam isto ruim?

Grupo 3: Não.

Grupo 1: Não atrapalhou, porque estava falando também.

Grupo 2: Assim está melhor.

P: Não incomoda essa pausa?

Grupo 4: Não.

Grupo 1: Não.

Todos os alunos disseram que o congelamento da tela para fazer a audiodescrição não atrapalhava e não incomodava. Essa informação é importante, pois o congelamento da tela pode ser a solução para tornar acessíveis vídeos educacionais que não foram desenhados para serem audiodescritos. 


\section{$\underline{\text { Repetição da explicação: }}$}

Em relação a repetição da explicação da 'equipe vermelha', após fazer a $\mathrm{AD}$, alguns alunos disseram que a repetição ajudava a reforçar a explicação. Já outros disseram que o vídeo fica mais repetitivo assim. São apresentados, a seguir, alguns trechos das falas dos alunos sobre a repetição da explicação:

Grupo 3: Repetido, porém mais explicativo.

Grupo 1: É igual ao outro, só que mais explicado.

Com os trechos destacados pode-se inferir que os alunos perceberam a diferença no formato do vídeo, mas não consideraram esta formatação ruim. Os alunos disseram que o vídeo com a $\mathrm{AD}$ era mais explicativo.

\section{Comparatória (vídeo audiodescrito x vídeo sem audiodescrição):}

Para analisar os aspectos comparatórios dos vídeos serão apresentados alguns trechos das discussões desenvolvidas após a apresentação dos vídeos. Inicialmente são apresentados alguns trechos das falas dos alunos durantes as discussões que ocorreram após a apresentação do vídeo sem $\mathrm{AD}$, quando os alunos tentavam responder a questão: como você explicaria o vídeo a um amigo?

\section{Grupo 1:}

Mesmo peso, ela consegui erguer em menos tempo. Então significa potência.

\section{Grupo 2:}

A bicicleta ele tem que pedalar mais, pois a luz ela vai clarear de acordo com a velocidade, né. E potência também, se tiver mais potência clareia mais.

\section{Grupo 3:}

A respeito do boneco, ficou claro que não houve deslocamento e nem trabalho, por que o boneco estava só pensando, isso é nulo. Não teve trabalho.

\section{Grupo 4:}

$O$ vídeo foi muito interessante. Ele fala sobre trabalho e potência. Foi feito um trabalho com deslocamento, ao mesmo tempo, um fez em 8,2 segundo e outro em 9 segundos. 
Após as discussões realizadas é possível perceber que os alunos compreenderam alguns elementos importantes do vídeo. Alguns alunos apenas disseram que o vídeo falava sobre trabalho e potência, outros alunos tentaram explicar os conceitos. Alunos do grupo 2 disseram que quanto maior a potência maior será a claridade do farol. No vídeo não foi apresentado essa explicação. E ela está correta, quanto mais rápido o garoto pedalar, mais trabalho será realizado e a potência será maior, pois a potência é o tempo gasto para realizar o trabalho, se o trabalho é feito em menos tempo maior será a potência. A explicação do grupo 2 mostra uma compreensão dos conceitos apresentados no vídeo.

Como a pergunta de questionamento foi aberta e livre, no sentido que os alunos pudessem falar o que quisessem, alguns explicaram melhor o que foi discutido no vídeo do que os outros. Contudo, pode-se perceber que os alunos entenderam que foram apresentados dois conceitos, e alguns alunos compreenderam esses conceitos.

Após estas discussões foi apresentado o vídeo com AD e solicitado aos alunos que dissessem como explicariam o vídeo a um amigo. Os alunos perceberam que o vídeo audiodescrito apresentava o mesmo que o vídeo sem audiodescrição, porém tinha mais explicações. São apresentados a seguir, alguns trechos das discussões desenvolvidas pelos grupos após a apresentação do vídeo audiodescrito:

\section{Grupo 1:}

$O$ vídeo fala sobre potência e trabalho, se não houver deslocamento e força não há trabalho, sem potência não gera energia. Gostamos da forma como foi explicada, forma de audiodescrição.

\section{Grupo 2:}

O que é aquele negócio que põe na bicicleta que acende a luz lá?

$P$ : Dínamo.

O que é isso?

\section{$[\ldots]$}

T: Eu acho que ficou mais fácil o segundo vídeo para entender.

$P: E$ isso que eu quero saber. Esse é um recurso para favorecer a aprendizagem da pessoa cega. Mas será que não favorece a aprendizagem das outras pessoas também?

T: Favorece sim. É mais fácil, ainda mais para mim, que meu cérebro não é muito bom.

\section{Grupo 3:}

Repetido mais porém mais explicativo. Fala sobre potência e trabalho. Trabalho negativo e positivo, movimento e deslocamento. $O$ que chamou mais atenção foi sobre o dinamo da bicicleta, que quanto mais gira mais aumenta a energia. 
Grupo 4:

Trabalho e potência. Esse vídeo apresentado vai ajudar muito as pessoas com baixa visão, e também outras. Gostamos dos dois, mas o segundo foi melhor, pois tinha uma boa explicação.

Com as falas dos participantes dos grupos é possível perceber que os alunos acharam o vídeo audiodescrito mais explicativo e em alguns momentos repetitivo. $\mathrm{O}$ aluno $\mathrm{T}$ deixou claro que para ele o vídeo com audiodescrição era melhor, pois tinha dificuldade para aprender. Com a apresentação do vídeo audiodescrito aparentemente o grupo 2 percebeu uma informação não compreendida antes, pois perguntou o que era um dínamo, e essa discussão foi apresentada com o vídeo sem audiodescrição. Essa informação pode indicar que com o vídeo audiodescrito é possível prestar a atenção a detalhes que passam despercebidos quando é utilizado um vídeo sem audiodescrição. O grupo 3 também informou que a parte do vídeo que explicava o funcionamento do dínamo havia lhe chamado a atenção. Novamente vale lembrar que esta explicação já havia sido apresentada anteriormente com o vídeo sem audiodescrição.

Ao término das discussões com os alunos foi solicitado que respondessem a uma última questão: qual vídeo você gostou mais? E por quê? A seguir são apresentadas as respostas dadas pelos grupos para a pergunta anteriormente apresentada:

\section{Grupol:}

Nós gostamos mais do vídeo com audiodescrição. Pois foi mais claro e nós achamos que favorece a todos.

\section{Grupo 2:}

Gostamos mais do segundo vídeo, porque ajuda a um deficiente visual e uma pessoa sem deficiência também, pois fica mais explicativo.

\section{$[\ldots]$}

Professora da turma: Comparando os dois vídeos. O segundo fez com que você entendesse mais?

T: Sim.

Professora da Turma: Então, é isso que ela quer saber. Embora seja o mesmo assunto, esse ele tem uma descrição a mais.

T: É mais explicado.

P: Você achou que você compreendeu mais com a audiodescrição?

T: Sim, deu para entender mais. Eu escrevi assim: eu gostei mais do segundo vídeo porque ele ajuda a pessoa com deficiência visual e agente a compreender. Eu iria colocar uma pessoa normal, mas eles também são normais, só são deficientes.

P: Agora fala de você?

T: Eu gostei. 
Grupo 3:

Gostamos mais do segundo (com AD) porque é mais fácil de entender.

Grupo 4:

$O$ segundo (com $A D$ ) foi mais diferenciado mais explicativo. Gostamos mais do vídeo com audiodescrição.

Todos os grupos relataram que gostaram mais do vídeo com audiodescrição. Para alguns alunos o vídeo audiodescrito é mais explicativo, o que ajuda a compreender o conceito. $\mathrm{O}$ aluno $\mathrm{T}$ tentou dar uma explicação politicamente correta, então foi lhe explicado que o que importava era sua opinião. Neste trabalho buscava-se entender se o vídeo audiodescrito poderia ser um recurso positivo no ensino de física para alunos sem deficiência, pois a ideia é construir uma proposta de ensino que seja boa para todos, na qual alunos com e sem deficiência visual possam aprender juntos.

\section{Conclusão}

Alunos cegos e com baixa visão que assistiram ao vídeo em grupo e individualmente consideraram a formatação da $\mathrm{AD}$ diferente, porém adequada $\mathrm{e}$ compreensível. Pode-se concluir que na impossibilidade de fazer a $\mathrm{AD}$ nos intervalos entre as falas, o congelamento da tela para fazer a $\mathrm{AD}$ é uma opção viável, e que pode alcançar bons resultados no ensino de conceitos mais abstratos como é o caso da física.

Alunos de uma turma da EJA também aprovaram a formatação do vídeo, considerando o mais repetitivo, porém mais explicativo. Segundo os alunos da EJA o congelamento da tela para fazer a $\mathrm{AD}$ não atrapalha a compreensão do vídeo.

$\mathrm{O}$ estudo mostra que o formato da AD utilizado na Espanha poderia ser utilizado em vídeos educacionais apresentados não somente a pessoas cegas, mas também a pessoas videntes, e as audiodescrições poderiam ser feitas durante o vídeo, não somente no início.

Embora os resultados deste estudo apontem que o congelamento da tela para fazer a $\mathrm{AD}$ é uma estratégia que pode alcançar bons resultados, é necessária uma investigação maior sobre o assunto. É preciso analisar a duração do vídeo e das audiodescrições, que podem interferir no resultado da aceitação da proposta. Incialmente concluímos que vídeos mais curtos são melhor aceitos, se o vídeo for muito demorado o congelamento da tela para fazer a AD pode incomodar, e interferir na atenção e no interesse do aluno vidente. A AD também precisa ser centrada na ação, 
pois se for audiodescrito aspectos da cena e de vestuário a $\mathrm{AD}$ ficará muito grande e pode se tornar desagradável.

\section{PROCEDURE FOR CONSTRUCTION AUDIO DESCRIPTION IN THE FREEZING SCREEN: A CASE STUDY FOR TEACH PHYSICS CONCEPTS}

ABSTRACT: This paper aims to describe the development of a procedure for an audio description of an educational resource for teaching Physics distributed by the Ministry of Education (MEC). For that used a not very common strategy to make audio description: freezing the screen. The audio-described video was tested on two occasions, first with a group of 14 people who were blind or had low vision. In a second step, the audio-described video was tested with a group of Youth and Adult Education (EJA) which had a student with low vision included. The results show that audio description made in times when the screen is frozen can be a solution to audio-describe ready videos that do not have enough breaks between the speeches so that audio description is made. The blind students considered the strategy was different, some liked more than others, but the strategy has been approved because the audio description complied their function: made verbal which was presented visually. For students of the EJA screen freezing is not seen as uncomfortable, and does not disturb the teaching and learning process.

KEYWORDS: Audio description. Physics teaching. Inclusive classes.

\section{REFERÊNCIAS}

AUDACITY OPEN SOURCE DEVELOPMENT TEAM. Audacity: the free, crossplatform audio editor and recorder [online]. 2011. Disponível em: <http://audacity.sourceforge.net/>. Acesso em: 06 abr. 2015.

BRASIL. IBTF - Instituto Brasileiro de Educação e Tecnologia de Formação a Distância. Projeto Acessa Física. Os Curiosos - trabalho e potência. Brasília: Ministério da Educação, 2010.

CAMARA, L.; ESPASA, E. The audio description of scientific multimedia. In: TRANSLATOR, [S.1.], v.17, n.2, p.415-437, 2011.

COREL CORPORATION. Corel video studio 12 [online]. 2011. Disponível em: <http://www.softonic.com.br/s/corel-videostudio-12>. Acesso em: 08 abr. 2015.

ORRICO, H.; CANEJO, E.; FOGLI, B. Uma reflexão sobre o cotidiano escolar de alunos com deficiência visual em classes regulares. In: GLAT, R. Educação inclusiva: cultura e cotidiana escolar. Rio de Janeiro: 7 Letras, 2009. p.116-136.

SILVA, F. et al. Reflexões sobre o pilar da áudio-descrição: "descreva o que você vê". Revista Brasileira de Tradução Visual, [S.1.], v.4, n.4, 2010. 
SNYDER, J. Audio description: the visual made verbal. International Congress Series, [S.1.], v.1282, p.935-939, 2005.

UDO, J.; FELS, D. Universal design on stage: live audio description for theatrical performances. Perspectives: Studies in Translatology, [S.1.], v.18, n.3, p.189-203, 2010 . 